\title{
4
}

\section{SINGLE-SEX SCHOOLS}

\section{Colleges}

Colleges in the United States began as male-only institutions, typically funded by religious denominations. What is now known as Harvard University was founded in 1636 to train clergy for the growing colonial population from England. Harvard, like other colleges founded before 1800, such as Yale, Princeton, William \& Mary, St. John's, and the University of Pennsylvania, only admitted men. The first coeducational college in the United States was Oberlin College in Ohio. Though founded in 1833, its first female students did not matriculate until 1837. The first women's colleges were Wesleyan College in Georgia, chartered in 1836, and Mount Holyoke College in western Massachusetts in 1837.

The exclusion of women from U.S. colleges reflects the cultural norms of the time. Men were educated to participate in the public sphere of business and politics whereas women were largely confined to the private sphere to care for home and family:

The colonial view of woman was simply that she was intellectually inferior-incapable, merely by reason of being a woman, of great thoughts. Her faculties were not worth training. Her place was in the home, where man assigned her a number of useful functions.

(Rudolph 1962, 307-308)

Women's colleges were founded with a mission to provide young women with an education of the same quality as that available to men. As historian Estelle B. Freedman noted, "When elite male institutions refused to educate women, the sister colleges of the East, like their counterparts elsewhere, took on the task themselves" (1979, 517-518). 
While some early women's institutions of higher learning were limited mostly to preparing women to be wives and mothers, others were designed to be seminaries for women, and others still had a more feminist goal of educating and empowering women to be successful leaders in any field (Horowitz 1993). The very idea of women attending college was opposed by some who felt that women belonged in the home, or that women were too frail for college, or would lose their femininity by attending college. In the famous Declaration of Sentiments emerging from the first Women's Rights Convention at Seneca Falls, one of the injuries on the part of man toward woman is that "He has denied her the facilities for obtaining a thorough education, all colleges being closed against her" (Stanton 1848). Social movements such as women's suffrage and the abolition movement contributed to the founding of some women's colleges (Langdon 2001). The founder of Wellesley College declared in The Spirit of the College that

We revolt against the slavery in which women are held by the customs of society - the broken health, the aimless lives, the subordinate position, the helpless dependence, the dishonesties and shams of so-called education. The Higher Education of Women is one of the great world battle-cries for freedom; for right against might. It is the cry of the oppressed slave. It is the assertion of absolute equality.

(Durant 1890, 3$)^{4}$

Only some founders of women's colleges publicly embraced tenets we would now call feminist (indeed, some felt the need to be quite circumspect in their politics), but in hindsight the establishment of significant number of high-quality women's colleges can be seen as a profoundly feminist accomplishment.

We have moved from an age when all U.S. colleges were single-sex (specifically male) to an era where single-sex colleges are a rarity. Of the 233 women's colleges in 1960 (Langdon 2001), less than 40 remain operating today, and there are only four men's colleges left. Women's colleges persist largely for what can be described as feminist reasons - to counteract the discrimination and sexism that is still evident in coeducational institutions, even though women now outnumber men in college (Goldin, Katz, \& Kuziemko 2006), and thus to provide a more supportive and favorable climate for women's learning and achievement (Langdon 2001).

Describing how these single-sex colleges have responded to the Transgender Exigency is the objective of this chapter.

\section{Women's colleges}

In 2013, Calliope Wong, a transgender woman who was a senior in high school, was denied admission to Smith College because her Federal Student Aid application form identified her as male. Her application and application fee were returned to her with the explanation that Smith College required applicants to be female at the time of admission. Wong certainly was not the first trans woman 
to seek admission to an all-women's college, but aided by the power of social media, she became a cause célèbre as her blog and her story were widely shared and became national news. Sympathetic Smith students formed Facebook groups in support, and national organizations such as the Transgender Legal Defense \& Education Fund rallied to her cause (see, for example, McQuade 2013). Wong ultimately chose to attend the University of Connecticut. Nonetheless, accounts of women's colleges' policies toward transgender applicants typically point to her efforts as a catalyst for women's colleges to clarify and publicize their policies. Admission policies involving transgender applicants ultimately turn on a question that resists but requires definition: "What does it mean to be a woman?" (Davis 2017, 82).

A year later, in May of 2014, Mills College became the first U.S. women's college to create a formal written admissions policy that includes transgender and gender fluid applicants. Their stated policy says "Mills admits self-identified women and people assigned female at birth who do not fit into the gender binary" (Mills 2020). Both Mills and Smith Colleges claim to have been open to transgender students before their official policy statements, but because such decisions were made on an ad hoc basis, there was a lack of clarity that could lead to controversies such as Wong's denial of admission to Smith (Bennett-Smith 2013; Martin 2013; Mitchell 2014). Smith College followed suit in May of 2015, and in a remarkably short period of time, most women's colleges in the United States have published policies allowing transgender women to apply.

As of April, 2020, a substantial majority of the 39 colleges that are members of the Women's College Coalition have revised their policies to permit transgender women as applicants, including Agnes Scott College, Alverno College, Barnard College, Bay Path University, Bennett College for Women, Brenau University, Bryn Mawr College, Cedar Crest College, College of Saint Benedict, Converse College, Cottey College, Hollins University, Mills College, Moore College of Art and Design, Mount Holyoke College, Russell Sage College, Salem College, Scripps College, Simmons University, Smith College, Spelman College, Stephens College, Sweet Briar College, Trinity Washington University, Wellesley College, and Wesleyan College. ${ }^{5}$

The precise definitional criteria at work at these institutions vary. At one end of the spectrum, some institutions merely require applicants to self-identify as women. Smith College's admission policy declares, "We welcome applicants who identify as women, including those who were assigned male at birth. No specific documentation is required to verify an applicant's gender" (Smith 2020, emphasis added). Bennett College for Women, Cedar Crest College, Mills College, Russell Sage College, Simmons University, are others who simply ask for self-identification, and Cedar Crest explicitly says "We do not require government issued documentation for purposes of identifying an applicant's gender identity" (Cedar Crest 2020). Mount Holyoke's admission webpage states simply, "We welcome applications from female, transgender and nonbinary students" (Mount Holyoke 2020). Put into the form of a regulatory definition (X counts as $\mathrm{Y}$ in context $\mathrm{C}$ ), then the sole definitive attribute is 
self-identification: Anyone who self-identifies as a woman (X) counts as a woman $(\mathrm{Y})$ in the context of applying to this institution (C).

A second common definitional approach goes a step further to require applicants to have an established history as women. The most common wording here requires applicants to "consistently self-identify and live as women." Similar wording to "consistently live and identify as women" can be found at a variety of schools, including Alverno, Barnard, Bryn Mawr, Spelman, and Wellesley. The FAQs for some colleges admission policies answer the obvious follow-up question of "What does it mean to consistently live and identify as a woman?" Barnard College states:

The applicant must identify herself as a woman and her application materials must support this self-identification. If the applicant is concerned about discrepancies in her application materials, she can speak with an admissions counselor or address any concerns in the essay or personal statement.

(Barnard 2019)

Hollins University similarly suggests that "The applicant must affirmatively identify herself as a woman and her application materials must support this self-identification" (Hollins 2020). It is not unusual at these institutions to seek supporting evidence of this self-identification (see also Bryn Mawr 2020; Wesleyan College 2020). Hence the regulatory definition could be formulated as: Anyone who consistently lives and identifies as a woman (X) counts as a woman (Y) in the context of applying to this institution (C).

The first definitional approach, explicitly requiring only self-identification, varies from this second approach primarily based on the reduced emphasis on the definitive attribute of duration. Sherie Gilmore-Cleveland, Director of Admissions of Mills College, states,

Students' self-identification does not have to match school documentation. If we have questions regarding a student's self-identification we inquire with the student based on their answers for clarification. The question of eligibility is based on the student's self-identification not a span of time.

(Gilmore-Cleveland 2020)

The President of Cedar Crest College, Dr. Elizabeth Meade, explained that decisions about gender identity sometimes emerge late in adolescence, and some students may come from homes where gender nonconformity might not feel comfortable or safe. A decision to transition to female might begin at the start of college, in other words. Accordingly, at Cedar Crest there is no specific requirement about the previous duration of an applicant's self-identification as a woman, but there is an "expectation that you will come to the college and continue to identify as a woman" (Meade 2020).

A third and less common definitional requirement is that applicants must have completed the process of legally changing their sex on official documents. 
According to the survey conducted by Vox (North 2017), Converse College, Cottey College, Salem College, and Scripps College will admit trans women if they have been legally assigned female. Sweet Briar College will admit a trans woman if she has been able to change her birth certificate to female. Stephens College admission policy says they "will also admit and enroll students who were not born female, but who identify and live as women; those students will need to provide legal documentation that they are legally women or that they are transitioning to female" (Stephens College 2018). Thus the regulatory definition would be anyone who is legally recognized as a woman $(\mathrm{X})$ counts as a woman $(\mathrm{Y})$ in the context of applying to this institution (C).

It is interesting to note that some institutions have loosened definitional criteria over time. In a 2017 survey, Hollins University required applicants to have legally and surgically transitioned (North 2017). As of 2020, their website uses the more common wording of requiring applicants to "consistently live and identify as women" (Hollins 2020).

The other area of variation is how different women's colleges treat students who transition from female to male while attending the institution. Some institutions require such students to leave, while others allow them to stay and graduate (North 2017). Converse College, for example, stresses that, "At the heart of Converse College is a women's college which offers a distinctive undergraduate program for women." Accordingly, taking a new self-identification seriously, the College does not permit students who transition to male (medically or legally) to continue their studies there, and may relocate them in terms of their campus housing (Converse College 2020). Wellesley College, on the other hand, explicitly states that they will "support" students who no longer identify as women after matriculation, allowing such students to stay at Wellesley or transfer to another institution (Wellesley College 2020). At Mills College, a transgender man not only was permitted to stay at the college but was elected student body president (Mitchell 2014).

Why have women's colleges moved to accept transgender applicants? The core value that seems to inform the changing policies is a commitment to the cause of feminism, which includes an acknowledgment that women have long endured discrimination. Priya Kandaswamy, a faculty member at Mills College who was on the subcommittee that drafted their new transgender policy, is quoted as saying "We strongly identify with our original mission, but we do think that women's colleges were originally founded to make education more accessible for those who were discriminated against based on gender and today that includes transgender" (in Mitchell 2014). Similarly, trans activist and law professor Dean Spade argued that trans people "fit" at women's colleges to create a space "that is about addressing gender oppression in higher ed" (Spade 2014). In a public letter by Wellesley College's president and Board of Trustees chair announcing the decision to consider any applicant who "lives as a woman and consistently identifies as a woman," it was noted that the origin of Wellesley was an important social-political accomplishment: "The creation of Wellesley College was a revolutionary act, challenging and confounding entrenched views about the roles and capacities of women." They 
further said, "Despite all the progress of the past century, women still face hurdles in realizing their potential." Accordingly, the feminist rationale for the formation of the College continues: "It is clear to us that the concept of a women's college, and the reasons for having one, are as valid today as they have been at any time in the past" (Gates \& Bottomly 2015).

As described in Chapter 2, feminist scholars were the first to describe the social and cultural variability of gender identity. Thus, for one graduate of Mills, allowing transgender women to apply was "the right move" to "remain a women's college while also having a more inclusive view of gender identity rather than relying on what it says on a person's documents" (in Mitchell 2014). It is also worth mentioning at this point that women generally report lower levels of transgender prejudice or "transphobia" than men do (Nagoshi et al. 2008).

Not everyone at women's colleges is happy with the admission of transgender students. There is a strand in contemporary feminist theory that will be examined at greater length in a later chapter known as "gender critical" feminism that questions whether cisgender women and transgender women share sufficient history and interests to be politically allied. At times the debates between feminist scholar/ activists have grown quite heated. In April 2020, Ninotska Love, one of the first openly transgender woman admitted to Wellesley College, was subjected to a series of hostile postings in the online platform Reddit in a discussion group titled Gender Critical Feminism (with roughly 60,000 members). ${ }^{6}$ The incident prompted Wellesley's president to send out an email reaffirming the College's commitment to "the basic human rights, dignity, and well-being of all Wellesley transgender and gender nonbinary community members" and declaring that the incident is "currently being investigated by both our Title IX coordinator and by Campus Police" (Johnson 2020).

To summarize the chapter thus far, women's colleges have responded to the Transgender Exigency in various ways. Some do not admit transgender women, and those that do vary in the definitional criteria used to decide who "counts" as a woman for the purposes of admission. The colleges and universities that admit transgender women do so, it would seem, because they see "women" as a category in which cisgender and transgender women share similar social-political status.

\section{Men's colleges}

As of 2020, the number of single-sex colleges for men has dwindled to four in the U.S.: Wabash College in Crawfordsville, Indiana; Morehouse College, a historically black men's college in Atlanta, Georgia; Hampden-Sydney College in HampdenSydney, Virginia; and Saint John's University in St. Joseph, Minnesota. Currently, two of the four do not admit transgender men (Jaschik 2019). St. John's University announced in November 2016 that it would consider transgender applicants:

In furtherance of our mission, tradition, and values as an undergraduate college for men, and in recognition of our changing world and evolving 
understanding of gender identity, Saint John's University will consider for undergraduate admission those applicants who consistently live and identify as men, regardless of the gender assigned to them at birth.

(SJU Trustees 2016)

The mission of St. John's University is specific to men:

Grounded in Catholic and Benedictine values and tradition, Saint John's University provides young men a distinctive residential liberal arts education, preparing them to reach their full potential and instilling in them the values and aspiration to lead lives of significance and principled achievement.

(SJU 2020)

Furthermore, the University identifies a set of values to which the institution is committed:

- Community built upon relationships of hospitality, respect, cooperation, and challenge.

- Openness to learning, inquiry, beauty, truth, and difference.

- Respect for persons, tradition, creativity, experience, faith, reason, and religious practice.

- Depth in understanding, relationships, faith, and spirituality.

- Sacredness of God, being, truth, place, nature, and knowledge.

- Passion for excellence, truth, learning, beauty, love, and personal growth.

Less than three years later, Morehouse College announced that it would admit transgender men, though if a student transitions from a man to a woman, that student would be asked to leave (Dodd 2019). Specifically, the policy states that,

In furtherance of our mission, tradition, and values as a men's college, and in recognition of our changing world and evolving understanding of gender identity, Morehouse will now consider for admission applicants who live and self-identify as men, regardless of the sex assigned to them at birth.

(Morehouse College 2019)

The mission statement of Morehouse College is worth quoting here:

The mission of Morehouse College is to develop men with disciplined minds who will lead lives of leadership and service. As the only historically black college or university dedicated to the development of men into leaders, we realize this mission by providing a world-class liberal arts education while emphasizing the intellectual and character development of our students. We assume a special responsibility for teaching the history and culture of black people.

(Morehouse College 2021) 
Like St. John's, Morehouse also identifies a series of values that shape the College's culture, including spirituality, community, accountability, trust, respect, integrity, honesty, civility, and compassion.

The point is that St. John's University and Morehouse College saw no conflict between their mission and values as men's colleges and a definition of "men" that includes transgender men. They both ask only that applicants "live and self-identify" as men. The definitive attributes identified here are twofold: To self-identify is an explicit act that is at the discretion of the applicant. To live as a man is obviously more vague, given that there are many ways of living as a man. In an email exchange with a former administrator at St. John's University, I learned that they do not necessarily expect evidence of a past commitment but rather are looking toward the future: There is no requirement for

legal documentation or previous requirement of identifying as a trans man. Our expectation has been that the trans applicant intends to identify as a man going forward. In other words, we would accept a trans student who intends to identify as a man throughout his college career.

Vice President for Student Development at the College of Saint Benedict, Mary Geller, who helped formulate the admission policy for both Saint Benedict and St. John's, confirmed that future intention is more important than past duration (Geller 2020). Thus, for all practical purposes at St. John's, the two attributes collapse into one and function in a manner similar to women's colleges that only require self-identification.

Hampden-Sydney College (or H-SC) only allows applicants who were assigned male at birth and identify as male (Jaschik 2019; Stimpert 2020). H-SC is the tenth oldest college in the United States, founded in 1775. It is located in Prince Edward County, notoriously known for having refused to abide by the Supreme Court's desegregation decision in Brown v. Topeka Board of Education (Green 2015). Vestiges of racism linger: In 2012, a group of about 40 students protested the reelection of Barack Obama as president, gathering outside the minority students' union. Students "shouted racial slurs, tossed bottles, set off fireworks and threatened physical violence," leading to four of the protesting students being disciplined (Winter 2012).

There is no question that there are progressive elements within the College and student body ${ }^{7}$ nonetheless, the College has earned a reputation overall of being conservative, and that conservatism apparently includes gender politics. For example, in 2016 the College first terminated, then reappointed, a visiting faculty member who had made public statements that were interpreted by some as advocating violence against transgender women who use a women's restroom (Kapsidelis 2016). More recently, the editor-in-chief of the student newspaper published an editorial titled "Transgender Lies Become Tyrannical" that, among other things, refers to the "false ideology of transgenderism" and considers the word "transphobic" to be a "nonsense word." Proclaiming that "The transgender delusion has carried on far 
enough," the author argues that opposition to "transgenderism" is being censored to a degree he considers tyrannical (Bredin 2019). The editorial is consistent with other conservative press coverage that treats transgender claims with skepticism, such as the headline "Women's college to admit male students posing as women" (Haverluck 2018). Implicit in the H-SC editorial is a commitment to biological determinism, though obviously it cannot be assumed that commitment is shared by the College's administration. Furthermore, the editorial swiftly received substantial criticism from parties from within and outside of H-SC (Black 2019; Gender Issues Committee 2019; Page 2019; Plichta-Kellar 2019; Stimpert 2019; Utzinger 2019).

Dr. Larry Stimpert, President of Hampden-Sydney College, explained that H-SC's commitment to form "good men and good citizens" dates back to the College's founding and continues to inform its policies today (2020). The admissions policy has evolved since 2011 from requiring that applicants be legally considered male (which, in theory, might allow a transgender applicant who had changed his birth certificate) to a 2017 requirement that applicants must be born and identify as male. When asked, President Stimpert did not identify a rationale for excluding transgender men other than the historic commitment of the College to being a men's college. With the University of Virginia beginning to admit women as undergraduates in 1970, and the Supreme Court requirement that the Virginia Military Institute admit women in 1996, H-SC is the last men's college in Virginia. Stimpert noted that an on-going concern of alumni and Board of Trustees is staying true to that commitment and tradition, and that there is resistance to changes that might be interpreted as moving the college toward becoming co-educational. Admitting transgender applicants could be perceived by some as just such a move. At the same time, Stimpert noted that there have been discussions among senior leadership about what to do if a current H-SC student transitioned to become a woman, and the unanimous response was that the College would support such a student to complete their degree at $\mathrm{H}-\mathrm{SC}$ rather than requiring the student to leave. ${ }^{8}$

Wabash College's Student Senate debated the question of admitting transgender men several times and rejected the idea because they felt admission would, in fact, hinder the College's pursuit of its mission. A spokesperson for Wabash told Inside Higher Ed that

the college's admissions policy is to evaluate candidates based on our singular and historic mission to be a liberal arts college for men chartered in the state of Indiana. All of our programs and policies are designed to support our mission." Asked if this meant that the college would admit only those classified by the government as male, he said, "legally male as defined by the state in which we are chartered."

(Jaschik 2017)

The explicit Mission Statement for Wabash College is not all that different from those of Morehouse or St. John's: "Wabash College educates men to think 
critically, act responsibly, lead effectively, and live humanely" (Wabash 2020). The Core Values advertised differ a bit from those of St. John's and Morehouse:

\section{Our Core Values}

\section{A rigorous liberal arts education that fosters}

- An appreciation for the intellectual and physical aspects of a good life

- An understanding of and appreciation for other cultures

\section{A personal context to teaching and learning that encourages}

- Candid, respectful, face-to-face conversations

- Freedom of thought

- A local scholarly community that creates lifelong relationships

\section{Individual responsibility and trust that are}

- Based on moral and ethical awareness

- Expressed in the Gentleman's Rule

- Required for leadership and teamwork

\section{A socially, economically, and ethnically diverse student body characterized by}

- A dedication to the serious pursuit of learning

- A culture of competition without malice

- A few years of residence, a lifetime of loyalty

\section{A tradition and philosophy of independence that}

- Keeps the College from external control

- Allows the Wabash community to shape significantly its own destiny

- Promotes independence and self-reliance in its students and graduates

(Wabash 2020)

One might interpret the emphasis on the Gentleman's Rule, competition, independence, and self-reliance as reflecting certain traditional masculine norms, and, indeed, there is evidence that at least some who opposed the admission of transgender students were motivated by a desire to maintain those norms. Though one needs to be careful not to overgeneralize, concerns have been expressed about the degree of sexism on campus. An account in the Chicago Tribune reported that some faculty "worry about the locker-room talk that sometimes erupts in classrooms, and the sexist attitudes some students express. Classroom 
discussions that touch on women's issues can be particularly strained" (Breslin 2001). A student editorial in the school newspaper, The Bachelor, defends Wabash as a Brotherhood of Men, and argued that "allowing a transgender individual here would violate our single-sex education as well as our Brotherhood" (Russel 2018). Criticizing the idea that "traditional male gender roles are harmful," the author defends the norms of "self-reliance, competition, and dominance" as "helpful in life." Echoing what I have described earlier as biological determinism, the student states, "I believe, as do many of my brothers, that a person is born with their sex determined" (Russel 2018). An equally strong statement about the biological basis for sex was articulated by a Student Senator who opposes the admission of transgender students: "I fully disagree with the idea that somehow somebody's perception in their mind changes their biological and genetic nature. Honestly the only common denominator when it comes to manhood is that genetic [component]. You are genetically male or female" (Block 2016, 3). Another student editorial argued, "it is unproductive to push for the admittance of women who claim to be men, not only because it would cease to make Wabash an all-male school, but it would utterly distort the nature of authentic manhood on campus" (Kaufman 2016).

The author's choice of words here, referring to "the nature of authentic manhood," is described as the language of essentialism (Schiappa 2003, 36). The language of essentialism refers to linguistic practices that reflect and depend on metaphysical absolutism - the belief that things have independent, "objective" structures or essences that are knowable "in themselves" (Barnes 1982, 79-83). One can discern such metaphysical absolutism when a distinction is made between "real" versus "apparent" Xs, as in this case between "the nature of authentic manhood" versus, implicitly, inauthentic or only apparent manhood. My argument in Defining Reality is that the language of essentialism is problematic for two reasons.

First, metaphysical absolutism is a mostly discredited philosophical doctrine when it comes to the practice of definition. Most philosophers have long since rejected the idea that we can identify timeless essences to describe what the "nature" of things are (Schiappa 2003, 39-41). Rather, as described in Chapter 2, our definitions of things, even in the physical sciences, depend on historically situated theories that change over time. Indeed, the point of Chapter 2 was to illustrate that we are at a moment of history when the question of how to define sex and gender, in particular, has never been so unsettled. Our culture is very far from a shared understanding of what "the nature of authentic manhood" is.

Second, deploying an alleged metaphysical distinction often obfuscates important social needs and values that are involved in acts of definition. As William James pointed out over a century ago, what we deem as an "essential" attribute of a thing is motivated by our purposes: "The 'essence' of a thing is that one of its properties which is so important for my interests that in comparison with it I may neglect the rest" $(1981,961) .{ }^{10}$ That is why, for example, Rebecca R. Helm stipulated, "as a developmental biologist, I define male/female as organisms producing sperm/eggs" (2020, emphasis added). 
If someone says "oh that is not 'real' music" or "he's not a 'real man'," we can be sure that the person has a preferred form of music or definition of manhood that s/he has deemed "essential," "authentic," or "real." Thus, in a definitional controversy, it is important to put one's cards on the table, so to speak, and identify the attributes that define "men" or "manhood" in the context of a college setting that one considers as most valuable. Only then can an assessment of whether transgender men should "count" as men in that context be made.

Wabash College and Hampden-Sydney rely on one's assigned sex at birth to define men and women. Why? ${ }^{11}$ At least in the case of Wabash, there is some evidence that the exclusion of transgender men is based on a belief in biological determinism:

[Our] brotherhood exists due to the very nature of our experience grounded in and shaped by our biological masculinity that sets us apart, but not above, women. Once we make one move to change this standard, it will compromise what manhood means at this institution and we will never recover from that.

(Kaufman 2016)

One might ask why Morehouse College and St. John's University decided otherwise? Both institutions' official policy state simply that they will admit transgender students "[i]n furtherance of our mission, tradition, and values as an undergraduate college for men, and in recognition of our changing world and evolving understanding of gender identity" (SJU 2016; Morehouse 2019).

It is worth noting that Morehouse and St. John's both coordinate with sibling all-women's colleges-Spelman College for Morehouse and the College of Saint Benedict for St. John's. The institutions share curriculum and access to certain facilities of the other. The conversation at Morehouse was prompted, at least in part, by Spelman College's decision in 2017 to admit transgender women (Jaschik 2019). I suspect it would be difficult to explain why a women's college should accept transgender applicants while their sibling men's college should not. If a commitment to self-identification and living as a woman is sufficient for the women's college, why should it not be functionally similar for the affiliated men's college? At this point in time, I am not aware of any affiliated sibling single-sex institutions that have conflicting policies.

To sum up, there are two regulatory definitions at work for men's colleges. Excluding transgender applicants, the first can be formulated as: Only those assigned the sex male at birth (X) count as men (Y) in the context of applying to this institution (C). Including transgender applicants, the second can be described as: Those who consistently live and identify as men, regardless of the gender assigned to them at birth $(\mathrm{X})$ count as men $(\mathrm{Y})$ in the context of applying to this institution (C). These competing regulatory definitions appear to be informed not only by competing approaches to definition (biological determinism versus self-identification) but also competing values associated with different visions of what it means to be a man. 


\section{What about single-sex K-12 schools?}

There are over 1,400 single-sex K-12 schools in the U.S. (Reilly 2019). Even focusing solely on high schools, the vast majority of single-sex schools do not have publicly stated policies about admitting transgender students. This does not mean that none do, but rather that "official" policy statements are rare and most handle the matter on a case-by-case basis. Many schools are still wrestling with the challenges of minors facing difficult choices and circumstances, and balancing a desire to serve students with care with the traditions associated with a single-sex school (Lane 2016). Not only are single-sex schools devising admission policies for transgender students, but they also must enact policies for whether to allow students who transition "out" of the school's single sex to stay or ask them to transfer. Meanwhile, transgender students across the nation report higher rates of depression, poor educational performance, and face greater risks of self-harm (GLSEN 2017). A number of high schools that my research assistants and I called or emailed for further information about their transgender admission policies did not respond. Those that did said that they had not received applications from students selfidentified as transgender, though it is possible some have applied without outing themselves as trans. ${ }^{12}$

Generally speaking, women's colleges have moved to a more inclusive model than most girls' secondary schools, despite the rise of public discussion and awareness about transgender issues at the high school level (Swartz 2017). A study done in spring 2017 gathered information from a sampling of 33 independent girls' schools and found that while 29 of the 33 reported having at least one transgender student, only eight had yet approved guidelines or policy for admissions decision (Mencher 2017). Reuters' news service contacted dozens of girls' schools in 2018 and found that "several said they had already developed transgender policies, some said they are having early discussions or have created taskforces and a number of others have taken no action" (Kvetenadze 2018). A chart provided by the National Coalition of Girls' Schools published in 2018 about independent all-girls schools suggests that the trend is toward admitting transgender girls on a case-by-case basis and relying on student selfidentification, at all educational levels, to determine eligibility (NCGS 2018). The NCGS provides a database of research and advice about serving the needs of transgender students (2020).

The International Boys' Schools Coalition lists a Transgender Task Force and Transgender Resources on their website, but does not publicly provide a position statement or policy recommendations. An internal document does not take a definitive position concerning the admission of transgender boys, but recommends an individualized and incremental approach:

Because each school is different and each boy's journey is unique, IBSC encourages schools to establish guiding principles and then to work with students and families on a case-by-case basis, rather than adopt rigid policies. 
This recommendation includes the enrollment process and students' full experiences at the school.

It is unclear how much interest there is among transgender boys to apply to allboys schools at the K-12 level. Former Head of School of the all-boys Belmont Hill School, Rick Melvoin, told me that "on my watch we would have absolutely welcomed the application of a trans boy," but no such applications were received. The Director of Admissions at an elite all-boys school on the east coast similarly told me that they had not received applicants who have identified themselves as transgender. A school counselor at an all-boys school told me that she was not aware of trans applicants, but there may well be applicants who are trans that refrain from disclosing that status in order to avoid discrimination in the application process.

Should a transgender boy apply to an all-boys' school? It is a difficult question. On one hand, past research has suggested that all-boys schools cultivate "more sexist environments" and that students at boys' schools "display more traditional forms of masculinity" than co-ed schools (Reilly 2019). One could imagine that trying to attend such a school at the age of 14 or 15 would be daunting for a transgender boy. Filmmaker and Professor of Philosophy and Gender Studies Thomas Keith agrees, contending that all-boys schools are more likely to be characterized by what Keith terms "bro culture," which

is made up mainly of boys and men who eschew the feminine and bond around their sexist and homophobic alliances with one another. Those of LGBTQ communities are typically used as fodder for insults, homophobic and transphobic punch lines in jokes, and people to deride and castigate in the service of bonding around their cisgender, heterosexual alliances to each other.

(Keith 2020)

It is reasonable to assume that trans boys who fear the risks of such a culture might want to avoid it.

On the other hand, it is clear that the leadership of some boys' schools is striving to improve the culture. A survey by the International Boys' Schools Coalition

found that boys' school leaders think the most important challenge facing their schools today is "healthy concepts of masculinity and relationships." Asked about the challenges that boys' schools will face over the next five years, a plurality of respondents said "gender issues".

(Reilly 2019)

Furthermore, some parents want to be convinced that "a boys' school will not be an incubator of male privilege and entitlement and misogyny" (Reilly 2019). Former Headmaster Melvoin told me that he felt the "bro culture" accusation was 
"dramatically exaggerated," and pointed to greater acceptance of self-identified gay students as an example of progress. He suggested that the environment of boys' schools can give boys more freedom to explore who they are than often is the case in coed schools (2020). Similarly, Jason Robinson, the Headmaster of St. Albans School, claims that boys' schools "provide an affirming environment for boys to 'interrogate unhealthy notions of masculinity' and discuss anxieties and frustrations without feeling self-conscious" (Reilly 2019).

Adam Howard, Professor of Education, is not so sure. His ongoing research of young alums (18-25) acknowledges that all-boys schools "are increasingly facilitating activities, experiences, discussions and so on around issues of gender and sexuality as well as privilege and social justice in response to what's happening in larger society." However, the alums in his research "largely describe these efforts as 'going through the motions' and not really a significant learning experience. Some participants, in fact, understand it as an 'attack' on men and masculinity" (2020; see also Howard 2019). Accordingly, it seems too soon to know whether the progress that some boys' schools report provides a climate that would be supportive of transgender students.

The more pressing issue for all-boys schools appears not to be admission policy but what to do when a student admitted and attending a boys' school decides to identify as a girl. The limited information available suggests that decisions about whether to allow a student to remain in a single-sex school after they transition is done on a case-by-case basis, and depends in part on where the student is in their education. For example, a student at a private boys' school in Virginia who attended the school beginning in kindergarten and who transitioned to identify as a woman the spring before their senior year requested and was given permission to graduate with their cohort.

\section{Conclusion}

As described in Chapter 1, regulatory definitions have three characteristics. First, regulatory definitions are formulated and authorized by recognized organizations or institutions. In this case, individual schools have been the organizations formulating the definitions. National organizations have refrained from advocating specific policies and definitions so far. There is, at this point in time, no particular legal or regulatory mechanism to compel a common definitional practice across the nation.

Second, regulatory definitions are designed to promote denotative conformity; that is, when using language, we want to be able to observe a phenomenon and agree that $\mathrm{X}$ is a $\mathrm{Y}$. It is clear that at this point in time, we lack denotative conformity with respect to gender identification for admission to single-sex schools because the definitions vary in a nontrivial manner. For some institutions, only cisgender males or females "count" as men or women for the purposes of admission. For others, a transgender applicant can count as an eligible boy or girl, woman or man, but the specific definitive attributes vary significantly, requiring only self-identification 
on one end of the spectrum, to some evidence of duration in the middle ("consistently live and identify as Y"), to having "legally" transitioned to the school's gender on the other end of the spectrum.

What this means is that we are still in a state of definitional rupture, wherein a specific person would be defined as a boy or man by one school and a girl or woman by another.

A third characteristic of regulatory definitions is that words are defined to serve one or more specific purpose and promote certain values or interests for those involved. It is reasonable to infer that when there are different and competing definitions, it is a result of competing values and interests at work. This point is, I believe, key to understanding why different single-sex schools have generated different definitions.

At the collegiate level, it seems reasonable to generalize that colleges permitting transgender women to apply have done so because such institutions often have feminist histories, values, and commitments-by which I mean a distrust of biological determinism (often used to justify the oppression of women), an acknowledgment that transgender women face discrimination similar (though not identical) to what cisgender women experience, and a desire to empower women for success in a world still dominated by sexism.

The four remaining men's colleges are currently divided 50/50. Both Saint John's University and Morehouse will admit applicants who "consistently live and identify as men," but there is little public indication of $w h y$. Saint John's University simply says the change was made "in recognition of our changing world and evolving understanding of gender identity" (SJU 2016). Morehouse College offers identical wording: "in recognition of our changing world and evolving understanding of gender identity" (Morehouse 2019). Again, it is worth noting that both schools work closely with partner women's schools. In either case, it is clear that neither institution sees a problematic conflict between their historical missions, traditions, and values as men's colleges and the admission of transgender men. The other two men's colleges, Wabash and Hampden-Sydney, are reluctant to make public statements explaining their decision, but from the limited available evidence it seems evident that there remains a commitment to biological determinism and traditional notions of masculinity.

There is a paucity of information about the motivations of single-sex K-12 institutions. Most note that they need to demonstrate care for their students while protecting the historical mission of their institutions. One could reasonably surmise that the competing values and interests are parallel to those facing colleges, with the added complication of the young age of K-12 students. The question of when young people are in position to decide about such a fundamental question as gender identity is a matter of contestation, but not one I can pursue here.

\section{Notes}

1 Quoted in Bennett-Smith (2013).

2 Love (2020) and Carapezza (2018). 
3 Quoted in Cregan (2018).

4 Durant gave the speech in the year Wellesley College was founded, 1875, though the speech was not published until 1890 for a gathering of the Alumnae Association (Taylor \& Glasscock 1975, 1). My thanks to Wellesley College library archivist Natalia Gutiérrez-Jones for her assistance.

5 This list comes from the research efforts of Wellesley undergraduate Grace (Yongxi) Pan and from North (2017).

6 The discussion group subsequently was banned, and moderators launched an invitationonly site with far fewer members called Ovarit.com (Fain 2020).

7 The school's Equity and Inclusion webpage states: "Hampden-Sydney College is committed to an inclusive structure that is coordinated and integrated, that celebrates all forms of diversity, and that ensures equitable educational and social benefits for all.' Such a statement, alumni and faculty from H-SC told me, primarily reflects the College's efforts to support minority and gay cisgender male students.

8 Interestingly, H-SC has a long-standing policy to allow the admission of daughters of faculty and staff. The numbers are quite low each year (zero to two). President Stimpert (2020) relayed that there was some controversy when one of these young women graduated first in her class. As senior staff has reviewed the College's admission policy, he reported, they have discussed whether ending the policy would reinforce the college's commitment to being a men's college.

9 It is not altogether clear what it means to be "legally male as defined by the state." To change one's birth certificate in Indiana requires a court order, and to change a driver's license requires either an updated birth certificate or State Form 55617 signed by a physician that the applicant successfully underwent treatment to permanently change gender (National Center for Transgender Equality 2020).

10 Scare quote marks added. James did not believe in essences in the way the idea was understood by most metaphysicians of his time, but is pointing out that the attributes we take as a thing's essence is a reflection of our own needs, interests, and values.

11 I asked the President and Director of Admissions at Wabash College to provide a brief explanation of why they do not admit transgender men applicants, and was told they had nothing to add other than what was reported in Jaschik (2017).

12 My thanks to Wellesley student Alex Hussey for her research efforts in this regard. 